\title{
An LC-MS Assay to Measure Superoxide Radicals and Hydrogen Peroxide in the Blood System
}

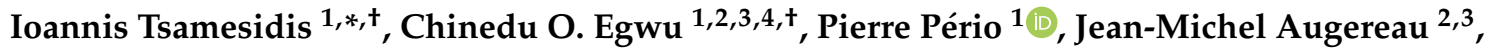 \\ Françoise Benoit-Vical ${ }^{2,3}$ and Karine Reybier ${ }^{1}$ \\ 1 Pharmadev, UMR 152, Université de Toulouse, IRD, UPS, 31400 Toulouse, France; \\ chinedu.egwu@lcc-toulouse.fr (C.O.E.); pierre.perio@univ-tlse3.fr (P.P.); \\ karine.reybier-vuattoux@univ-tlse3.fr (K.R.) \\ 2 CNRS, LCC, Laboratoire de Chimie de Coordination, Université de Toulouse, 31077 Toulouse CEDEX 4, \\ France; jean-michel.augereau@lcc-toulouse.fr (J.-M.A.); francoise.vical@inserm.fr (F.B.-V.) \\ 3 Institut de Pharmacologie et de Biologie Structurale, IPBS, Université de Toulouse, CNRS, UPS, \\ 31077 Toulouse CEDEX 4, France \\ 4 Alex-Ekwueme Federal University, Ndufu-Alike Ikwo P.M.B. 1010, Ebonyi State, Nigeria \\ * Correspondence: johntsame@gmail.com \\ + These authors contributed equally to this work.
}

Received: 13 March 2020; Accepted: 24 April 2020; Published: 28 April 2020

\begin{abstract}
Red blood cells are constantly exposed to reactive species under physiological or pathological conditions or during administration of xenobiotics. Regardless of the source, its accurate quantification is paramount in the area of theragnostics, which had been elusive up until now. Even if there are a lot of approaches to evaluate the oxidative stress, very sensitive methods are missing for the blood system. We therefore sought to apply a highly sensitive approach, by liquid chromatography coupled to mass spectrometry (UPLC-MS), for the quantification of reactive species such as superoxide radical and hydrogen peroxide using dihydroethidium (DHE) and coumarin boronic acid (CBA) probes respectively through the detection of 2-hydroxyethidium $\left(2 \mathrm{OH}-\mathrm{E}^{+}\right)$and 7-hydroxycoumarin $(\mathrm{COH})$. The use of the high-resolution mass spectrometry associated to UPLC ensured a selective detection of superoxide and hydrogen peroxide in the blood system under diverse conditions such as oxidized red blood cells (RBCs), untreated and treated parasitized RBCs. Moreover, this technique allowed the determination of reactive species in human plasma. This protocol provides a huge opportunity for in-depth study of several pathological conditions vis-a-vis their treatment in modern medicine.
\end{abstract}

Keywords: liquid-chromatography; mass spectrometry; superoxide radicals; hydrogen peroxide species; red blood cells; human plasma; microvesicles; Plasmodium falciparum

\section{Introduction}

To unravel the biological roles of reactive oxygen species (ROS), the ability to detect, identify and quantify the reactive species involved at the cellular level is paramount. Oxidative stress results from an imbalance between the antioxidant system and generation of reactive species that normally takes place in healthy organism. Under conditions of oxidative stress, the increase in reactive species production leads to subsequent alteration of membrane lipids, proteins and nucleic acids [1,2]. Oxidative stress can be measured directly by the quantification of reactive oxygen, nitrogen species or indirectly by measuring the level of oxidative markers such as lipid peroxidation or antioxidant enzymes or glutathione [3]. The direct and indirect methods are usually complementary to each other in stating the oxidative state of a cell, but the direct approach is often more challenging. Several direct approaches exist for eukaryotic cells among them luminescent assays (fluorescent, chemiluminescent and bioluminescent) [4] and electron paramagnetic resonance (EPR) [5]. 
Fluorescent assays use certain sensors such as $\mathrm{H}_{2}$ DCFDA $\left(2^{\prime}, 7^{\prime}\right.$-dichlorodihydrofluorescein diacetate) or CM-DCFDA, chloromethyl derivative of $\mathrm{H}_{2}$ DCFDA, DHE (dihydroethidium, also called hydroethidine), CBA (B-(2-oxo-2H-1-benzopyran-7-yl)-boronic acid or coumarin boronic acid).

However, these probes lack specificity and sensitivity for the targeted reactive species, which limit their application and subsequent interpretation of results. Indeed, the probes often form several adducts, which absorb or emit light at similar wavelengths and are also prone to redox-cycling [6]. In the same manner, the use of EPR assays has its shortfalls. Although EPR is described as the "gold standard" for the detection of radical species, the spin adducts formed after reaction of the probe with the specific radical is rapidly metabolized into the cell [7]. In these conditions, EPR analysis is suitable only for the detection of extracellular reactive species. To overcome the problem of non-selectivity, associations of fluorescent measurements with liquid chromatography (LC) were reported for eukaryotic cells for the detection of specific adducts such as 2-hydroxyethidium $\left(2 \mathrm{OH}-\mathrm{E}^{+}\right)$ for superoxide and 7-hydroxycoumarin $(\mathrm{COH})$ for hydrogen peroxide or peroxynitrite [8-11] (Figure 1). Moreover, the use of mass spectrometry coupled with LC has been proposed to unequivocally detect the desired adduct formed by the reaction of the probe with the targeted species $[8,9,12-15]$.

In the case of red blood cells (RBCs), the options that offer the required specificity and sensitivity are limited. The need for the study of ROS in the blood system is increasingly pertinent because of several physiological (e.g., cell signaling), blood storage in transfusion units [16-19] (e.g., anaerobic and cryopreservation), pathological (e.g., thalassemia and malaria) and chemotherapeutic (e.g., antimalarial, anticancer, etc.) conditions that exacerbate oxidative stress [20,21].

Until now, methods in use are especially fluorescence using $\mathrm{H}_{2}$ DCFDA [6,22-24] and EPR using DMPO as a spin trap [25] for the direct quantification of reactive oxygen species in RBCs and human plasma. The shortcomings of these prevailing approaches buttress the need for a newer and more reliable approach. In this article, we report how the LC-MS method can be successfully applied to erythrocytes and human plasma for quantifying superoxide radicals and its reduced form, hydrogen peroxide in the erythrocyte system under diverse conditions.

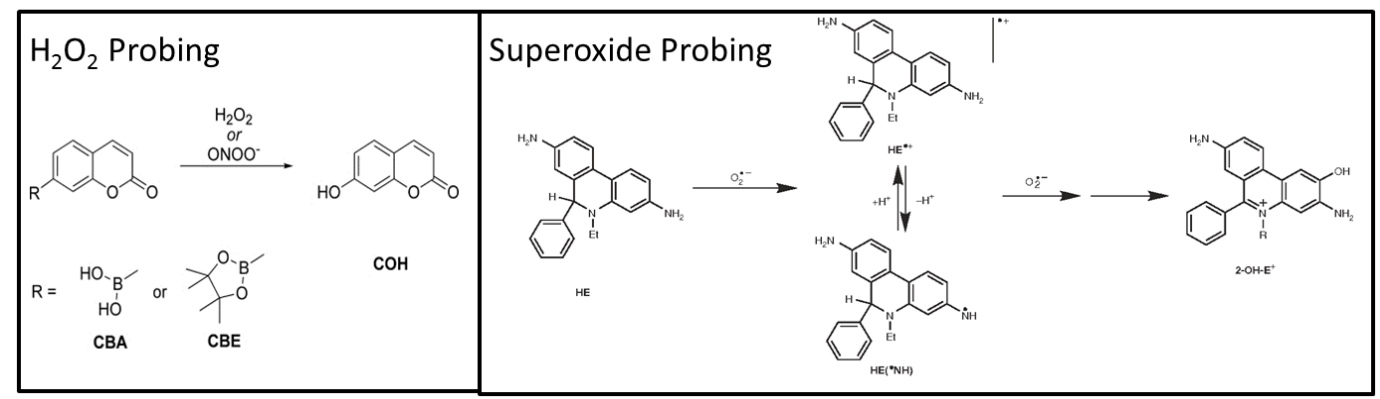

Figure 1. Formation of specific adducts from reaction of probes with targeted reactive oxygen species. CBA: Coumarin boronic acid (detected as the formiate adduct $\mathrm{C}_{10} \mathrm{H}_{8} \mathrm{BO}_{6}{ }^{-} ; \mathrm{m} / \mathrm{z} 235.0419$ (th)), CBE: pinacolate ester of Coumarin boronic acid, $\mathrm{COH}$ : 7-hydroxycoumarin (detected as the deprotonated form $\mathrm{C}_{9} \mathrm{H}_{5} \mathrm{O}_{3}{ }^{-} ; \mathrm{m} / \mathrm{z} 161.0244$ (th)), DHE: dihydroethidium (detected as the protonated form $\mathrm{C}_{21} \mathrm{H}_{22} \mathrm{~N}_{3}{ }^{+}$; $m / z 316.1808$ (th)) and $2 \mathrm{OH}-\mathrm{E}^{+}$: 2-hydroxyethidium (detected as a cation $\mathrm{C}_{21} \mathrm{H}_{20} \mathrm{~N}_{3} \mathrm{O}^{+} ; m / z 330,1601$ (th)).

\section{Materials and Methods}

\subsection{Materials}

DMSO, 99.9\%, DHE (dihydroethidium), CBA (Coumarin boronic acid), COH (7-hydroxycoumarin), $>98.0 \%$ (HPLC), phenylhydrazine, artemisinin and RPMI 1640 medium were purchased from Sigma-Aldrich, St. Quentin Fallavier, France. Formic acid (Optima for LC-MS), ammonium acetate (Optima for LC-MS), acetonitrile (HPLC gradient grade), methanol, (HPLC gradient grade) and phosphate buffer saline were purchased from Thermo Fisher Scientific, Illkirch, France. $2 \mathrm{OH}-\mathrm{E}^{+}$was synthesized following the protocol of Zielonka et al. [8]. 


\subsection{Biological Materials}

\subsubsection{Blood Sample Collection}

Blood samples from healthy donors were collected in EDTA-containing tubes in the morning from Etablissement Français du Sang (EFS, Toulouse, France), responsible for ethic statements. The samples were centrifuged at $200 \times g$ for $5 \mathrm{~min}$ at $4{ }^{\circ} \mathrm{C}$ to separate the cellular components from the plasma and stored at $-80{ }^{\circ} \mathrm{C}$ until the analyses were carried out.

\subsubsection{Cultivation of Plasmodium falciparum-Infected Red Blood Cells (RBCs).}

Freshly drawn blood (Rh+) from healthy adults (both sexes were used) and anticoagulated with heparin was stored in citrate-phosphate-dextrose with adenine (CPDA-1) prior to use. RBCs were separated from plasma and leukocytes after centrifugation and subsequently washed three times in RPMI 1640 medium. The laboratory strains of Plasmodium falciparum (mycoplasma-free) were grown according to standard protocols. The parasites were maintained in RPMI 1640 medium supplemented with 5\% human serum at 2\% hematocrit. Both strains FcB1-Columbia and F32-Tanzania were used for developing the protocol. The $P$. falciparum parasites were maintained synchronized by treating the culture with $5 \%(w / w)$ D-sorbitol (1:10) at the ring stage of the erythrocytic cycle (0-12 h) as described by Lambros and Vanderberg [26]. If a very high parasitemia ( $\geq 80 \%)$ is required, a column chromatographic technique involving magnetic columns is used to increase the synchrony and percentage parasitemia at the trophozoite stage [27].

Before analysis the parasite culture pellet (FcB1-Columbia strain) is collected by centrifugation at $469 \times g$ for $5 \mathrm{~min}$ in a $50 \mathrm{~mL}$ tube. The parasitized RBCs (pRBCs) were diluted appropriately in phosphate buffer saline (PBS) to obtain 10-20 million cells/mL in $1.5 \mathrm{~mL}$ eppendorf tubes.

According to the study conducted, pRBCs were incubated with $200 \mathrm{nM}$ ART for $1 \mathrm{~h}$.

\subsubsection{Oxidation of Red Blood Cells}

RBCs were separated from whole blood by centrifugation at $200 \times \mathrm{g}$ for $5 \mathrm{~min}$ at $4{ }^{\circ} \mathrm{C}$ and were also washed three times in sterile phosphate buffer saline (PBS) avoiding presence of white blood cells. The RBCs $\left(5 \times 10^{6}\right.$ cells) were incubated overnight $(12 \mathrm{~h})$ at $300 \mathrm{rpm}$ at $4{ }^{\circ} \mathrm{C}$ in an Eppendorf Thermomix (Hamburg, Germany) with the ROS inducer. For the present experiment (see Figure 2 for details) RBCs were incubated with $1 \mathrm{mM}$ phenylhydrazine (PHZ) in PBS. PHZ was removed the next day by washing three times with PBS. Before analysis the suspension was centrifuged at $200 \times g$ for 5 min at $4{ }^{\circ} \mathrm{C}$ to obtain a pellet.

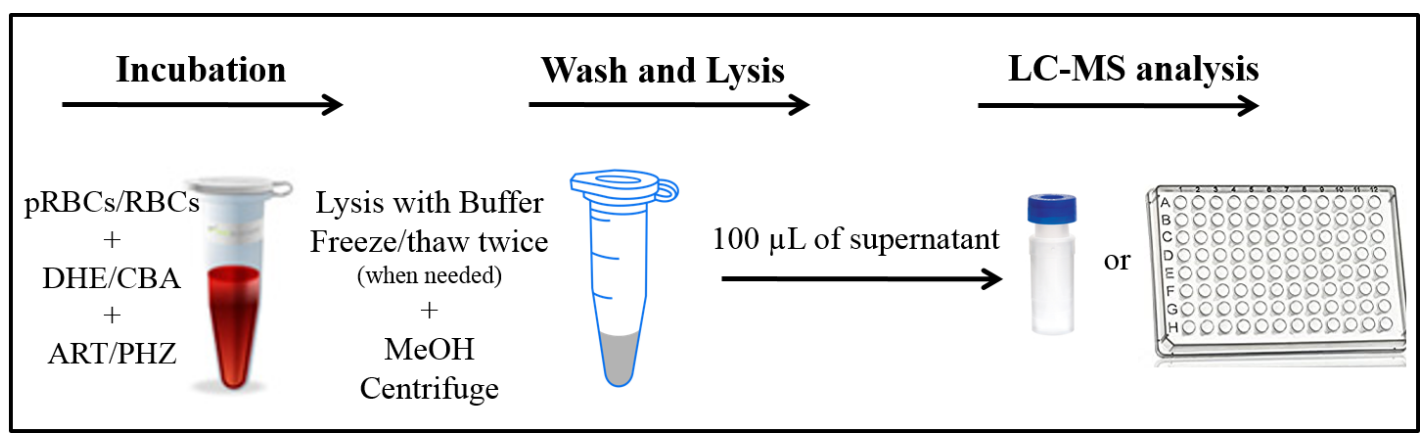

Figure 2. Summary of the sample the parasitized red blood cell (pRBC) or red blood cell (RBC) preparation or the LC-MS analysis. Note: pRBCs: Plasmodium infected red blood cells, $\mathrm{MeOH}$ : methanol, DHE: dihydroethydium, ART: artemisinin. 


\subsubsection{Human Plasma}

Human plasma was separated from whole blood by centrifugation at $200 \times g$ for 5 min at $4{ }^{\circ} \mathrm{C}$. Plasma was then transferred in a new Eppendorf while white blood cells and pellets were totally removed. The plasma was then diluted 100 times in PBS.

\subsection{LC-MS Assays}

\subsubsection{LC-MS Measurements}

The LC-MS analysis was performed using an Ultimate 3000 UPLC system consisting of a solvent organizer SRD-3600 with a degasser, a high pressure binary gradient pump HPG-3400RS, a thermostated autosampler WPS3000TRS, an oven TCC3000SD and an UV-Visible detector DAD3000 (ThermoFisher Scientific, Courtaboeuf, France) coupled with LTQ-Orbitrap XL ETD mass spectrometer (ThermoFisher Scientific, Courtaboeuf, France).

The 2 mobile phases used for analyses consisted of A) $20 \mathrm{mM}$ ammonium acetate solution prepared in water (MilliQ) $\mathrm{pH} 9$ and B) acetonitrile for superoxide detection and in A) $0.1 \%$ formic acid solution prepared in water (MilliQ) and B) $0.1 \%$ formic acid prepared in acetonitrile for hydrogen peroxide detection.

For $2 \mathrm{OH}-\mathrm{E}^{+}$analysis, UPLC was performed using an UPLC Kinetex EVO C18 $1.7 \mu \mathrm{m}$ column $(2.1 \mathrm{~mm} \times 100 \mathrm{~mm})$ at $50{ }^{\circ} \mathrm{C}$; flow rate $400 \mu \mathrm{L} / \mathrm{min}$ using the following chromatographic conditions: $75 \% \mathrm{~A} / 25 \% \mathrm{~B}$ to $95 \% \mathrm{~B}$ in 2.5 min with a non-linear gradient (concave, "curve 3"), hold for $0.5 \mathrm{~min}$ and then back to the initial conditions in $0.1 \mathrm{~min}$. The MS analysis was performed in positive electrospray ionization (ESI) mode: spray voltage $4.2 \mathrm{kV}$; capillary temperature $300{ }^{\circ} \mathrm{C}$, resolution 15000 .

For $\mathrm{COH}$ analysis a UPLC Kinetex C18 $1.7 \mu \mathrm{m}$ column $(2.1 \mathrm{~mm} \times 100 \mathrm{~mm})$ was used at $40{ }^{\circ} \mathrm{C}$; flow rate $500 \mu \mathrm{L} / \mathrm{min}$ using the following chromatographic conditions: $85 \% \mathrm{~A} / 15 \% \mathrm{~B}$ to $75 \% \mathrm{~B}$ in $2 \mathrm{~min}$, to $98 \% \mathrm{~B} / 2 \% \mathrm{~A}$ in $0.1 \mathrm{~min}$. The MS analysis was performed in negative electrospray ionization (ESI) mode: spray voltage $3.2 \mathrm{kV}$ and capillary temperature $300{ }^{\circ} \mathrm{C}$, resolution 7500 . The peaks of the chromatogram were integrated using Xcalibur software.

Before each measurement, a calibration curve was prepared. The 2-hydroxyethidium $\left(2-\mathrm{OH}-\mathrm{E}^{+}\right)$ standard solutions were freshly prepared on the day of experiment by diluting the stock solution $(50 \mu \mathrm{M})$ serially in the mobile phase A to obtain 6 standards from 10 to $500 \mathrm{nM}$. The COH standard solutions were also freshly prepared on the day of experiment by diluting the stock solution (10 $\mathrm{mM})$ serially in aqueous methanol $(50 \% \mathrm{v} / \mathrm{v})$. Examples of the corresponding curves are presented in Figure 3A,B. LOD and LOQ were calculated from several calibration curves giving the following values LOD $7 \mathrm{nM} / \mathrm{LOQ} 24 \mathrm{~nm}$ for superoxide and LOD $11 \mathrm{nM} / \mathrm{LOQ} 37 \mathrm{nM}$ for hydrogen peroxide.

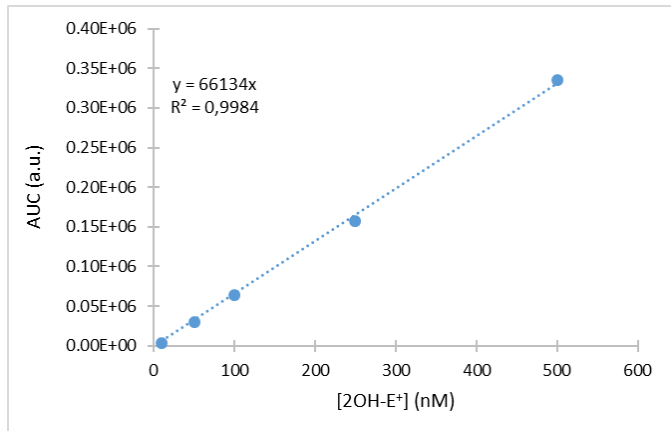

A

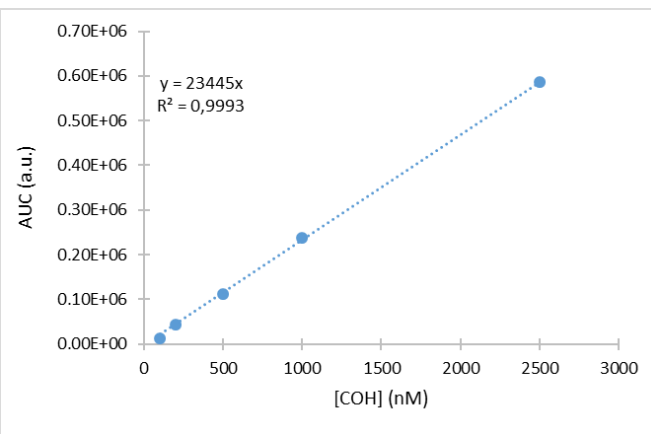

B

Figure 3. Example of the calibration curve obtained with $2 \mathrm{OH}-\mathrm{E}^{+}(\mathbf{A})$ and $\mathrm{COH}(\mathbf{B})$. 


\subsubsection{Analysis of Oxidized Red Blood Cells}

Fifty microliters of the pellet were probed with $20 \mu \mathrm{M}$ of DHE or CBA and incubated for $30 \mathrm{~min}$. After centrifugation at $200 \times g$ for $5 \mathrm{~min}$ at $4{ }^{\circ} \mathrm{C}$, the supernatant was collected for analysis. Then $100 \mu \mathrm{L}$ of a hemolysis buffer $(5 \mathrm{mmol} / \mathrm{L}$ sodium phosphate and $1 \mathrm{mmol} / \mathrm{L}$ EDTA, $\mathrm{pH}$ 8.0) were added to the pellet and vortexed rigorously. Before analysis, $100 \mu \mathrm{L}$ of methanol were added to the lysed cells and to the supernatant to precipitate the cell debris. After centrifugation at $5000 \times \mathrm{g}$ for $30 \mathrm{~min}$ at $4{ }^{\circ} \mathrm{C}$, both samples were analyzed by the LC-MS analysis.

\subsubsection{Analysis of Plasmodium Falciparum Parasitized Red Blood Cells}

A suspension of pRBCs was probed with $20 \mu \mathrm{M}$ of DHE or CBA and incubated alongside with artemisinin (ART; $200 \mathrm{nM}$ ). After 1-hour incubation the suspension was centrifuged at $200 \times g$ for $5 \mathrm{~min}$. After removing the supernatant, the pellet was washed 2-3 times in $100 \mu \mathrm{L}$ PBS. To lyse the cells, $100 \mu \mathrm{L}$ of the hemolysis buffer $(5 \mathrm{mmol} / \mathrm{L}$ sodium phosphate and $1 \mathrm{mmol} / \mathrm{L}$ EDTA, pH 8.0) were added to the pellet placed on ice. To facilitate the lysing of the plasmodial membranes 2 freeze thaw cycles twice were performed at $-80^{\circ} \mathrm{C}$ and water bath respectively for about $30 \mathrm{~min}$. Before analysis, $100 \mu \mathrm{L}$ of methanol were added to the lysed cells and to the supernatant to precipitate the cell debris. After centrifugation at $5000 \times \mathrm{g}$ for $30 \mathrm{~min}$ at $4{ }^{\circ} \mathrm{C}$, both samples were analyzed by the LC-MS analysis.

As a control, the red blood cells were incubated with the vehicle only, i.e., using an equal amount of solvent as was used for the incubations with the chemicals of interest.

\subsubsection{Analysis of Human Plasma}

The diluted plasma was probed with $20 \mu \mathrm{M}$ of DHE or CBA. To separate plasma membrane vesicles (PMVs) from other components (ghost, cell fragments and debris), the suspension was centrifuged at $5000 \times g$ for $10 \mathrm{~min}$ at $4{ }^{\circ} \mathrm{C}$. The supernatant was then collected and $100 \mu \mathrm{L}$ of methanol was then added to lyse PMVs $[28,29]$. The sample was further centrifuged at $5000 \times \mathrm{g}$ for $30 \mathrm{~min}$ at $4{ }^{\circ} \mathrm{C}$ and analyzed.

\section{Results and Discussion}

\subsection{Detection of Reactive Oxygen Species in Oxidized RBCs}

Treatment of RBCs with PHZ, a strong oxidant, causes selective association of oxidized alpha-globin chains with the membrane skeleton, which reduces RBC deformability, a characteristic of beta-thalassemia. Furthermore, PHZ induces deleterious oxidations in the components of erythrocytes, generating ROS and reacting with hemoglobin by changing the oxyhemoglobin into methemoglobin, hemichromes and other byproducts [30-32]. The nature and amount of ROS produced in such conditions were investigated using LC-MS. An example of the mass chromatogram is presented in Figure 4A,B. The corresponding concentration of superoxide and hydrogen peroxide deduced from the calibration curves are presented in Figure 5. As demonstrated, a significant increase (approximately 4 folds) of both species was observed for PHZ treated RBC in comparison with untreated ones. The concentration increased from 10 to $50 \mathrm{nM}$ for $\mathrm{O}_{2}{ }^{\bullet-}$ and from 25 to $100 \mathrm{nM}$ for $\mathrm{H}_{2} \mathrm{O}_{2}$. 

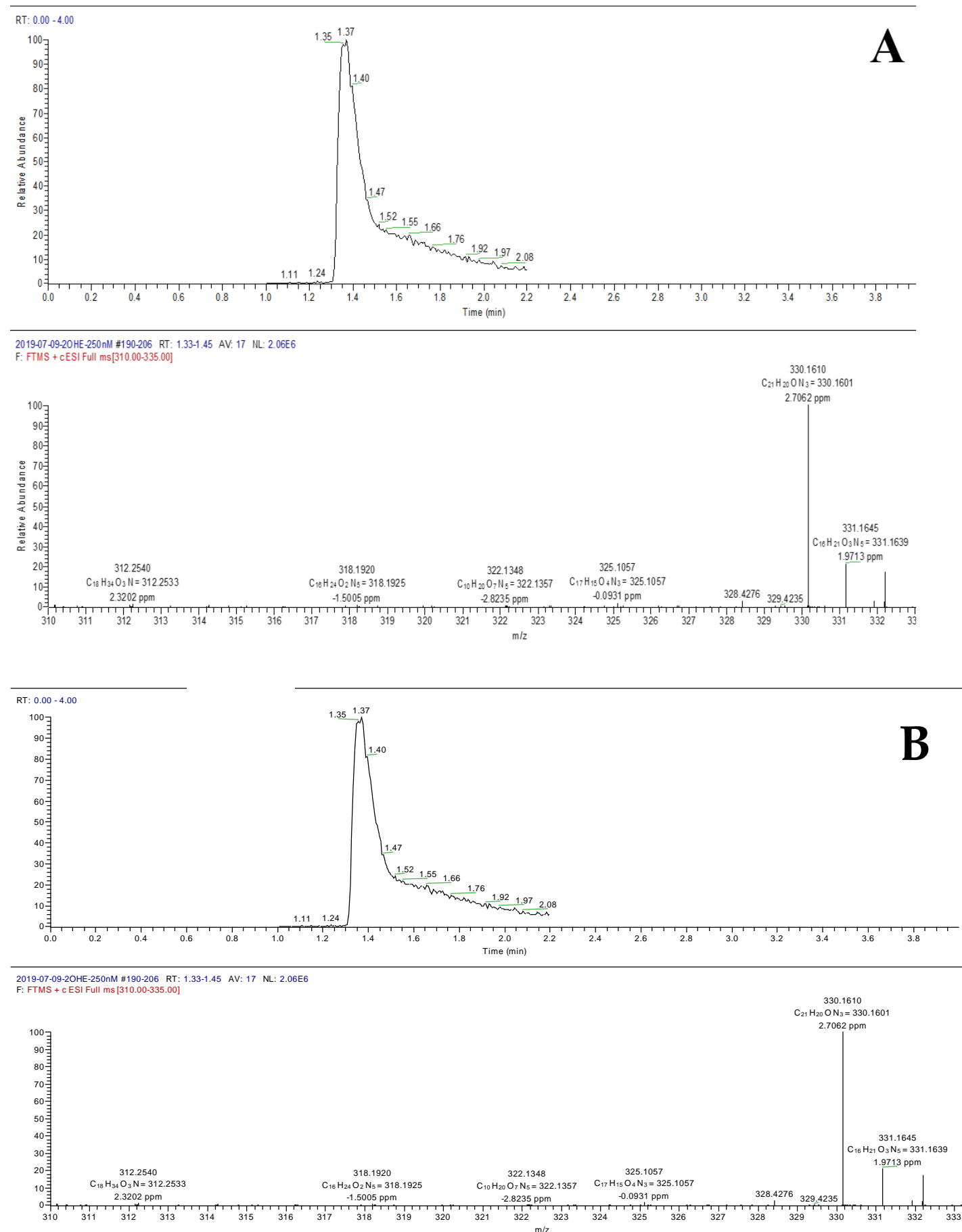

Figure 4. Extracted mass chromatogram based on $\mathrm{m} / \mathrm{z} 330$ and corresponding $2 \mathrm{OH}-\mathrm{E}^{+}$mass spectrum (A). Extracted mass chromatogram base on $\mathrm{m} / \mathrm{z} 161$ and corresponding $\mathrm{COH}$ mass spectrum (B). 


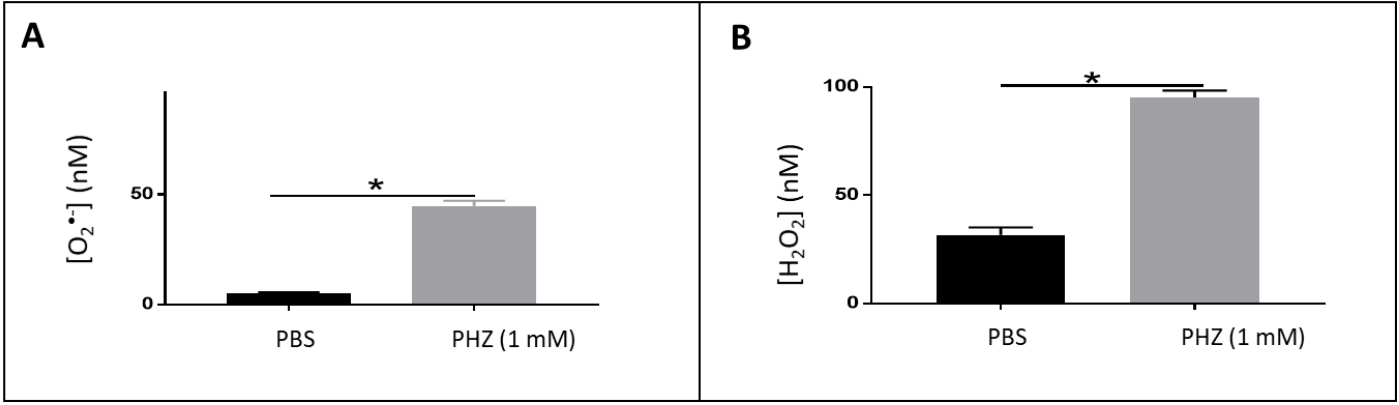

Figure 5. Quantification of superoxide (A) and $\mathrm{H}_{2} \mathrm{O}_{2}(\mathbf{B})$ in $\mathrm{PHZ}$ treated RBCs comparatively with untreated ones. Note: results represent six replicates from three independent experiments, value $=$ mean \pm SD. ${ }^{*}=$ Significant $(p<0.05)$.

\subsection{Detection of Reactive Oxygen Species in Plasmodium Falciparum Infected Erythrocytes}

To produce essential amino acids needed for its development, Plasmodium falciparum digests hemoglobin of the RBC releasing ferrous iron $\left(\mathrm{Fe}^{2+}\right)$ species, heme that can reoxidize to form superoxide radicals and then hydrogen peroxide. Moreover, artemisinin (ART) and its derivatives act as antimalarials by inducing an overproduction of ROS after activation by heme or free iron [33]. However, the nature of the radicals produced as well as their amount has not yet been determined. Herein we applied the LC-MS to characterize the species forms both in treated and untreated pRBC. The corresponding results are presented in Figure 6. The incubation of parasitized erythrocytes for $1 \mathrm{~h}$ resulted in a significant increase (approximately 2 fold) in the production of $\mathrm{O}_{2}{ }^{\bullet-}$ radicals and $\mathrm{H}_{2} \mathrm{O}_{2}$ species. It is of note that the concentration of ART used was very low $(200 \mathrm{nM})$, which underlines the sensitivity of the method.

Methods allowing the specific detection and quantification of reactive species is highly needed as several clinical trials and preclinical studies [34] of new antimalarial drugs include ROS measurements to study and better understand immune response [35], disease state and progression and the health-enhancing effects of the tested antimalarials against Plasmodium species.

A

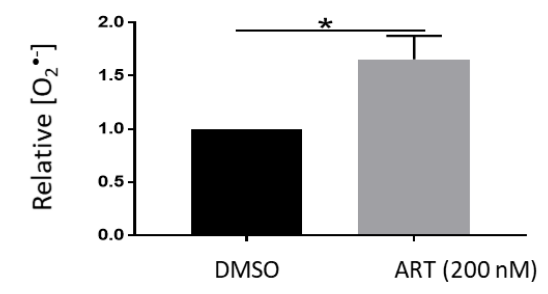

B

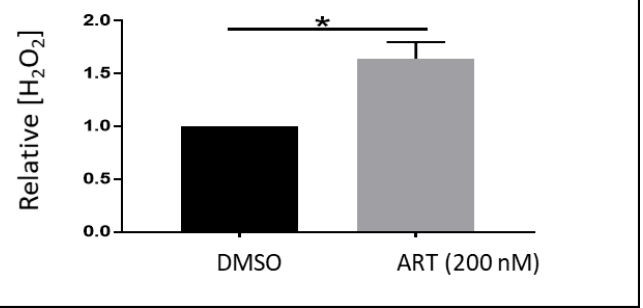

Figure 6. Quantification of superoxide (A) and $\mathrm{H}_{2} \mathrm{O}_{2}$ (B) in parasitized RBCs treated with artemisinin comparatively to the untreated ones. Note: results represents six replicates from three independent experiments, value $=$ mean \pm SD. ${ }^{*}=$ Significant $(p<0.05)$.

\subsection{Detection of Reactive Oxygen Species in Human Plasma}

Plasma membrane-vesicles (PMVs) are released into circulation because of normal and stress/pathogenic conditions. PMVs are also referred as microparticles (MPs), microvesicles (MVs) or rarely, ectosomes. They are submembrane fragments shed from the plasma membrane of red cells, platelets, white cells during cell growth, activation, proliferation, senescence and apoptosis [36]. PMVs contain a pro-oxidant or antioxidant machinery that may produce or scavenge ROS metabolic enzymes (direct effect) and can modify (activate or inhibit) the ROS content in the extra-as well as the intracellular compartments [37]. Taking into consideration that plasma contains PMVs that directly or 
indirectly produce or scavenge ROS, we investigated the exact amount of superoxide radicals and $\mathrm{H}_{2} \mathrm{O}_{2}$ species levels in the human plasma of healthy donors. It was impossible to detect ROS in non-diluted plasma as the matrix effect was observed inducing a shift of the retention time (Figure 7A,B). A 100-fold dilution of the plasma allowed us to achieve the right retention time (Figure 7C). The same phenomenon (matrix effect in non-diluted plasma) was also observed for $\mathrm{H}_{2} \mathrm{O}_{2}$ species detection. Moreover, a second peak was detected for a retention time of $1.82 \mathrm{~min}$. This peak is attributable to a little percentage of DHE (eluted at this retention time) oxidized during ionization into $2 \mathrm{OH}-\mathrm{E}^{+}$. This second peak was not taken into account in the integration of the peak because it did not originate from superoxide.

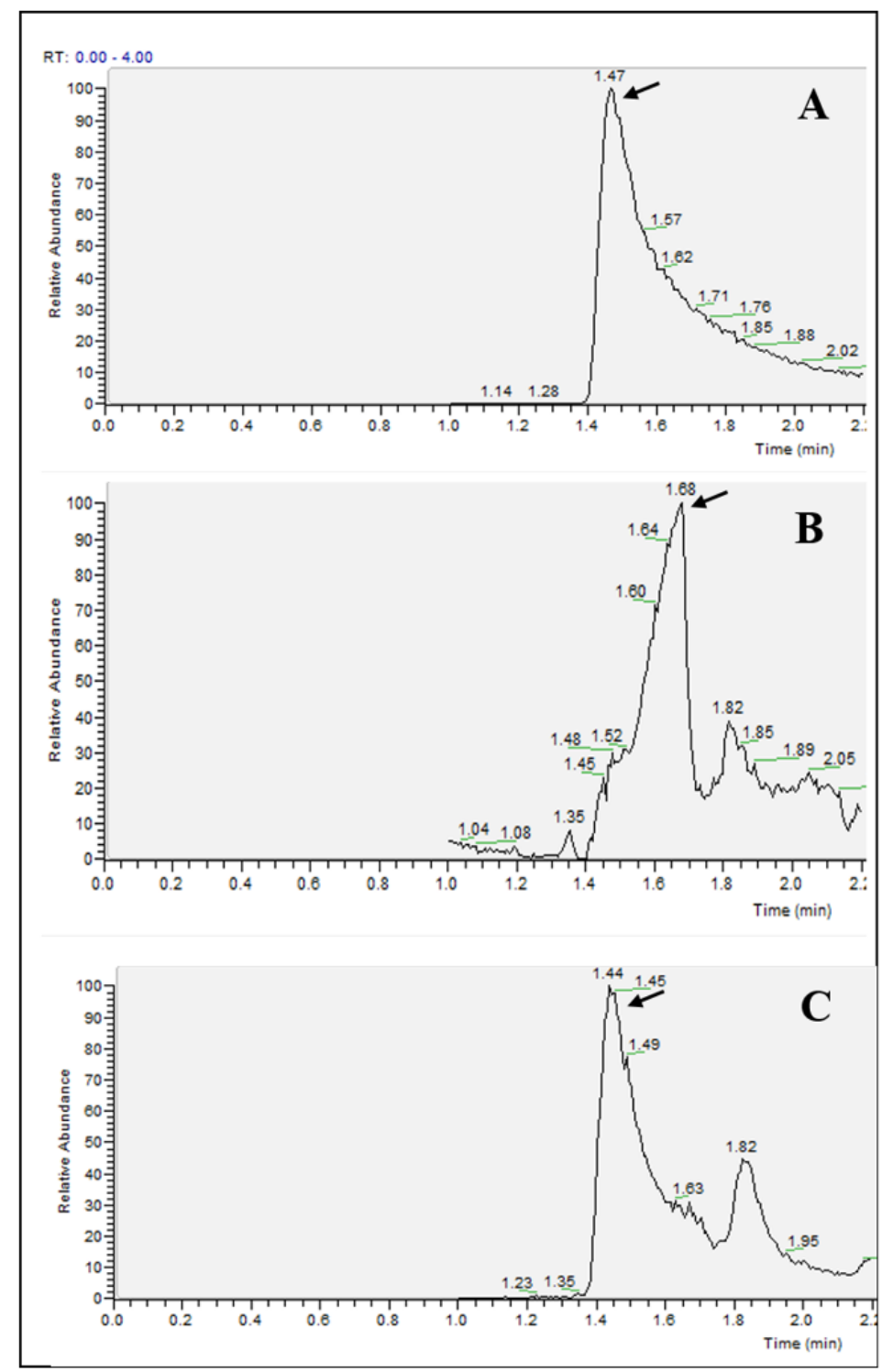

Figure 7. Extracted mass chromatogram base on $\mathrm{m} / \mathrm{z} 330$ (A) standard $500 \mathrm{nM} 2 \mathrm{OH}-\mathrm{E}^{+}$, (B) non diluted human plasma and (C) human plasma diluted 100 times.

The LC-MS allowed us to detect ROS in healthy donor's plasma at $201 \pm 13 \mathrm{nM}$ for superoxide and $50 \pm 9 \mathrm{nM}$ for hydrogen peroxide. This result is of particular interest because it is highly desirable to measure abnormal levels of ROS in clinical samples of patients with iron overload disorders such as thalassemia and myelodysplastic syndromes [38] to better predict progression, and to improve the treatment outcomes of iron chelators. 


\section{Conclusions}

The use of the high-resolution mass spectrometry associated to UPLC ensured a selective detection of superoxide and hydrogen peroxide in the blood system under diverse conditions such as oxidized RBCs, untreated and treated parasitized RBCs. Moreover, this technique allowed the determination of reactive species in human plasma. This novel method appears to be of great interest due to the increasing consideration given to ROS in various pathological states and the development of therapeutics agents.

Author Contributions: I.T. and C.O.E. executed all the experiments while P.P. performed the L.C.M.S. runs, integrated and analyzed all the L.C.M.S. results. J.-M.A. and F.B.-V. contributed in the plasmodial cell culture and harvest and in the design of some of the experiments. K.R. designed the experiments and interpreted the data. I.T., C.O.E. and K.R. performed the conceptualization and wrote the original draft and all the co-authors made significant contributions in writing and improving the manuscript. All authors have read and agreed to the published version of the manuscript.

Funding: This research received no external funding.

Conflicts of Interest: The authors declare no conflict of interest.

\section{References}

1. Santo, A.; Zhu, H.; Li, Y.R. Free radicals: From health to disease. React. Oxyg. Species 2016. [CrossRef]

2. Li, Y.R.; Trush, M. Defining ROS in biology and medicine. React. Oxyg. Species 2016, 1, 9. [CrossRef]

3. Katerji, M.; Filippova, M.; Duerksen-Hughes, P. Approaches and methods to measure oxidative stress in clinical samples: Research applications in the cancer field. Oxidative Med. Cell. Longev. 2019, 2019, 1279250. [CrossRef]

4. Zielonka, J.; Kalyanaraman, B. Small-molecule luminescent probes for the detection of cellular oxidizing and nitrating species. Free Radic. Biol. Med. 2018, 128, 3-22. [CrossRef]

5. Abbas, K.; Babić, N.; Peyrot, F. Use of spin traps to detect superoxide production in living cells by electron paramagnetic resonance (EPR) spectroscopy. Methods 2016, 109, 31-43. [CrossRef]

6. Dikalov, S.I.; Harrison, D.G. Methods for detection of mitochondrial and cellular reactive oxygen species. Antioxid. Redox Signal. 2014, 20, 372-382. [CrossRef]

7. Hawkins, C.L.; Davies, M.J. Detection and characterisation of radicals in biological materials using EPR methodology. Biochim. Biophys. Acta-Gen. Subj. 2014, 1840, 708-721. [CrossRef]

8. Zielonka, J.; Vasquez-Vivar, J.; Kalyanaraman, B. Detection of 2-hydroxyethidium in cellular systems: A unique marker product of superoxide and hydroethidine. Nat. Protoc. 2008, 3, 8. [CrossRef]

9. Kalyanaraman, B.; Hardy, M.; Podsiadly, R.; Cheng, G.; Zielonka, J. Recent developments in detection of superoxide radical anion and hydrogen peroxide: Opportunities, challenges, and implications in redox signaling. Arch. Biochem. Biophys. 2017, 617, 38-47. [CrossRef]

10. Kalyanaraman, B.; Dranka, B.P.; Hardy, M.; Michalski, R.; Zielonka, J. HPLC-based monitoring of products formed from hydroethidine-based fluorogenic probes-The ultimate approach for intra- and extracellular superoxide detection. Biochim. Biophys. Acta-Gen. Subj. 2014, 1840, 739-744. [CrossRef]

11. Zielonka, J.; Hardy, M.; Kalyanaraman, B. HPLC study of oxidation products of hydroethidine in chemical and biological systems: Ramifications in superoxide measurements. Free Radic. Biol. Med. 2009, 46, 329-338. [CrossRef]

12. Xiao, Y.; Meierhofer, D. Are hydroethidine-based probes reliable for reactive oxygen species detection? Antioxid. Redox Signal. 2019, 359-367. [CrossRef]

13. Wang, Z.Y.; Li, Y.; Chang, W.Q.; Zheng, J.Y.; Li, P.; Liu, L.F.; Xin, G.Z. Development and validation of a LC/MS-based method for the measurement of intracellular superoxide anion. Anal. Chim. Acta 2018, 999, 107-113. [CrossRef]

14. Sikora, A.; Zielonka, J.; Lopez, M.; Joseph, J.; Kalyanaraman, B. Direct oxidation of boronates by peroxynitrite: Mechanism and implications in fluorescence imaging of peroxynitrite. Free Radic. Biol. Med. 2009, 47, 1401-1407. [CrossRef] 
15. Zielonka, J.; Sikora, A.; Hardy, M.; Joseph, J.; Dranka, B.P.; Kalyanaraman, B. Boronate probes as diagnostic tools for real time monitoring of peroxynitrite and hydroperoxides. Chem. Res. Toxicol. 2012, 25, 1793-1799. [CrossRef]

16. Yoshida, T.; Prudent, M.; D'Alessandro, A. Red blood cell storage lesion: Causes and potential clinical consequences. Blood Transfus. 2019, 17, 27.

17. Bardyn, M.; Tissot, J.D.; Prudent, M. Oxidative stress and antioxidant defenses during blood processing and storage of erythrocyte concentrates. Transfus. Clin. Biol. 2018, 25, 96-100. [CrossRef]

18. Antonelou, M.H.; Kriebardis, A.G.; Stamoulis, K.E.; Economou-Petersen, E.; Margaritis, L.H.; Papassideri, I.S. Red blood cell aging markers during storage in citrate-phosphate-dextrose- saline-adenine-glucose-mannitol. Transfusion 2010, 50, 376-389. [CrossRef]

19. Delobel, J.; Prudent, M.; Rubin, O.; Crettaz, D.; Tissot, J.D.; Lion, N. Subcellular fractionation of stored red blood cells reveals a compartment-based protein carbonylation evolution. J. Proteom. 2012, 76, 181-193. [CrossRef]

20. Postma, N.S.; Mommers, E.C.; Eling, W.M.C.; Zuidema, J. Oxidative stress in malaria; implications for prevention and therapy. Pharm. World Sci. 1996, 18, 121-129. [CrossRef]

21. Robert, A.; Benoit-Vical, F.; Claparols, C.; Meunier, B. The antimalarial drug artemisinin alkylates heme in infected mice. Proc. Natl. Acad. Sci. USA 2005, 102, 13676-13680. [CrossRef]

22. Held, P. An introduction to reactive oxygen species measurement of ROS in cells. Biotek Instrum. 2012, 5, 1-12.

23. Tsamesidis, I.; Pouroutzidou, G.K.; Lymperaki, E.; Kazeli, K.; Lioutas, C.B.; Christodoulou, E.; Perio, P.; Reybier, K.; Pantaleo, A.; Kontonasaki, E. Effect of ion doping in silica-based nanoparticles on the hemolytic and oxidative activity in contact with human erythrocytes. Chem. Biol. Interact. 2020, 318, 108974. [CrossRef]

24. Wojtala, A.; Bonora, M.; Malinska, D.; Pinton, P.; Duszynski, J.; Wieckowski, M.R. Methods to monitor ROS production by fluorescence microscopy and fluorometry. In Methods in Enzymology; Elsevier: Cambridge, MA, USA, 2014; Volume 542, pp. 243-262. [CrossRef]

25. Cassagnes, L.E.; Rakotoarivelo, N.; Sirigu, S.; Pério, P.; Najahi, E.; Chavas, L.M.G.; Thompson, A.; Gayon, R.; Ferry, G.; Boutin, J.A.; et al. Role of quinone reductase 2 in the antimalarial properties of indolone-type derivatives. Molecules 2017, 22, 210. [CrossRef] [PubMed]

26. Lambros, C.; Vanderberg, J.P. Synchronization of Plasmodium falciparum erythrocytic stages in culture. J. Parasitol. 1979, 418-420. [CrossRef]

27. Ribaut, C.; Berry, A.; Chevalley, S.; Reybier, K.; Morlais, I.; Parzy, D.; Nepveu, F.; Benoit-Vical, F.; Valentin, A. Concentration and purification by magnetic separation of the erythrocytic stages of all human Plasmodium species. Malar. J. 2008, 7, 45. [CrossRef]

28. Fang, X.; Duan, Y.; Adkins, G.B.; Pan, S.; Wang, H.; Liu, Y.; Zhong, W. Highly efficient exosome isolation and protein analysis by an integrated nanomaterial-based platform. Anal. Chem. 2018, 90, 2787-2795. [CrossRef]

29. György, B.; Módos, K.; Pállinger, É.; Pálóczi, K.; Pásztói, M.; Misják, P.; Deli, M.A.; Sipos, Á.; Szalai, A.; Voszka, I.; et al. Detection and isolation of cell-derived microparticles are compromised by protein complexes resulting from shared biophysical parameters. Blood 2011, 117, e39-e48. [CrossRef]

30. Berger, J. Phenylhydrazine haematotoxicity. J. Appl. Biomed. 2007, 5, 125-130. [CrossRef]

31. Jarolim, P.; Lahav, M.; Liu, S.C.; Palek, J. Effect of hemoglobin oxidation products on the stability of red cell membrane skeletons and the associations of skeletal proteins: Correlation with a release of hemin. Blood 1990, 2125-2131. [CrossRef]

32. Pantaleo, A.; Ferru, E.; Pau, M.C.; Khadjavi, A.; Mandili, G.; Mattè, A.; Spano, A.; De Franceschi, L.; Pippia, P.; Turrini, F. Band 3 erythrocyte membrane protein acts as redox stress sensor leading to its phosphorylation by p72 Syk. Oxidative Med. Cell. Longev. 2016, 2016, 6051093. [CrossRef] [PubMed]

33. Gopalakrishnan, A.M.; Kumar, N. Antimalarial action of artesunate involves DNA damage mediated by reactive oxygen species. Antimicrob. Agents Chemother. 2015, 59, 317-325. [CrossRef]

34. Kannan, D.; Yadav, N.; Ahmad, S.; Namdev, P.; Bhattacharjee, S.; Lochab, B.; Singh, S. Pre-clinical study of iron oxide nanoparticles fortified artesunate for efficient targeting of malarial parasite. EBioMedicine 2019, 45, 261-277. [CrossRef] [PubMed]

35. Joos, C.; Marrama, L.; Polson, H.E.J.; Corre, S.; Diatta, A.M.; Diouf, B.; Trape, J.F.; Tall, A.; Longacre, S.; Perraut, R. Clinical protection from falciparum malaria correlates with neutrophil respiratory bursts induced by merozoites opsonized with human serum antibodies. PLoS ONE 2010, 5, e9871. [CrossRef] 
36. Antwi-Baffour, S.S. Molecular characterisation of plasma membrane-derived vesicles. J. Biomed. Sci. 2015, 22, 68. [CrossRef]

37. Bodega, G.; Alique, M.; Puebla, L.; Carracedo, J.; Ramírez, R.M. Microvesicles: ROS scavengers and ROS producers. J. Extracell. Vesicles 2019, 8, 1626654. [CrossRef]

38. Gonçalves, A.C.; Cortesão, E.; Oliveiros, B.; Alves, V.; Espadana, A.I.; Rito, L.; Magalhães, E.; Lobão, M.J.; Pereira, A.; Nascimento Costa, J.M.; et al. Oxidative stress and mitochondrial dysfunction play a role in myelodysplastic syndrome development, diagnosis, and prognosis: A pilot study. Free Radic. Res. 2015, 49, 1081-1094. [CrossRef]

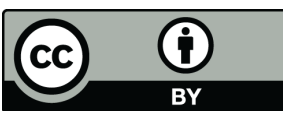

(C) 2020 by the authors. Licensee MDPI, Basel, Switzerland. This article is an open access article distributed under the terms and conditions of the Creative Commons Attribution (CC BY) license (http://creativecommons.org/licenses/by/4.0/). 